\section{Apathy rewards misconduct - and everybody suffers}

Sir - Louis Guenin's Commentary (Nature 402, 577; 1999) is a welcome contribution to defining misconduct in scientific research. A related problem is that research misconduct is all too frequently seen as a victimless crime to which indifference is an adequate response. As recently as October 1997 the heads of the UK research councils were reported in Research Fortnight to have decided that misconduct is a lesser evil than the encumbrance of any mechanism to prevent it.

More recently, the research councils have had a change of heart and published policies on misconduct. But there is no mechanism for ensuring compliance, so institutions can whitewash misconduct or sweep it under the carpet. Since investigations bring adverse publicity, these are tempting options. Nor is there any adequate means of protecting honest whistle-blowers - a gaping hole, given the fraudster-friendly nature of UK libel law.

All honest scientists are victims of scientists who commit misconduct. Jobs in science, research funds and journal space are all scarce. Every job occupied, every grant received and every paper published by someone who engages in misconduct deprives at least one honest scientist of an opportunity to which he or she was entitled. To that can be added the waste of time and resources when other scientists attempt to use fraudulent or misrepresented results.

Scientific fraud resembles financial fraud in that it can bring undeserved remuneration and power, a salient difference being that in scientific fraud the ill-gotten gains are automatically institutionally laundered.

Herbert N. Arst Jr

Department of Infectious Diseases, Imperial College School of Medicine, London W12 ONN, UK

\section{End of impact factors?}

Sir-Does the expansion of the Internet and journals' online publishing strategies herald the end of 'impact factors'? Many scientific publications now have online versions, often freely available. As Internet access is pervasive (and increasing), busy scientists can now sit with their morning coffee and use a computer search engine to look for articles in their narrow area of interest. The computer database can be much more exhaustive, user-friendly and up-to-date than its old-fashioned paper counterpart. As a result, the researcher can now in effect have a customized 'table of contents' generated on demand.

The overall effect of this practice seems likely to be a shift in reader emphasis away from particular ('high-impact') journals as reference sources, and an increasing importance of specific articles, rather than the journal in which they are published. If this is indeed the case, continued emphasis on 'impact factors' as currently calculated would seem to be misguided, and the concept will need to be redefined. John Brunstein

Department of Virology, Haartman Institute, University of Helsinki, Haartmaninkatu 3 , 00290 Helsinki, Finland

\section{Nucleic acids revelation delayed by a sceptic}

Sir-Although the discovery of nucleic acids, mentioned in Peter Little's News and Views article "The book of genes" (Nature 402, 467; 1999), was published in 1871, the Swiss physiologist Johann Friedrich Miescher (1844-95) actually made the discovery two years earlier.

Working in Tübingen between autumn 1868 and 1869, Miescher isolated the new substance from cells of pus (leukocytes) obtained from discarded bandages from the local surgical clinic. In order to find the chemical constitution of nuclei, he removed the proteinaceous cytoplasmic substances of the cells by digestion with gastric juice (containing the protease pepsin) from pigs' stomachs and with hydrochloric acid. The material of the naked nuclei that he obtained and called "nuclein" contained 14 per cent nitrogen, 2 per cent sulphur and 6 per cent phosphorus pentoxide, making it very rich in phosphorus.

The final studies were made in the autumn of 1869, because on 21 August that year Miescher wrote to his parents: "I still have to complete the definitive analysis of the nuclear substances." And the paper is dated "Basel, October 1869". Miescher's teacher and laboratory chief in Tübingen, the German biochemist Felix Hoppe-Seyler (1825-95), received the manuscript, but was sceptical about the rather revolutionary findings of a beginner. Therefore, he decided to repeat the experiments, and he printed Miescher's paper "Über die chemische Zusammensetzung der Eiterzellen" only after he had verified them.

Hoppe-Seyler wrote in a footnote that the publication was delayed very much "through several unforeseen circumstances". In a paper of his own he writes: "I have to emphasize that in all points as far as I have examined Miescher's statements I have to confirm the latter fully."

Friedrich Katscher

Mariahilfer Str. 133, A-1150 Vienna, Austria

\section{Proteomics is getting easier in some ways...}

Sir - The report on proteomics (Nature 402, 715; 1999) was an excellent summary of current attempts to build on knowledge of the genomes. I would point out, however, that $2 \mathrm{D}$ gel electrophoresis is no longer "notoriously difficult to carry out". My undergraduates routinely perform 2D gels, often getting ten good gels on the first try. Also, while hydrophobic proteins present a challenge, some of them can indeed be obtained on gels using SDS/urea treatment of the sample; this process is compatible with current gel technology. Joan L. Slonczewski

Department of Biology, Kenyon College, Gambier, Ohio 43022, USA

\section{.... and should be treated the same as genomics}

Sir - Your Briefing on proteomics was valuable and informative. Unfortunately, the Opinion (Nature 402, 703; 1999) was less so. The writer notes that "Nature intends to play its part by insisting on conceptual insights from among the great quantities of information that [proteomics studies] will certainly deliver".

I disagree with requiring such standards for studies of proteins when very different standards appear to be applied to sequencing studies. For example, the same issue contained two articles describing the sequencing of chromosomes 2 and 4 from Arabidopsis thaliana. As a researcher from outside the plant field, I did not find conceptual insights in this information. The speculations regarding mitochondrial gene exchange and relative proportions of receptor-signalling proteins were interesting, but were similar to speculations that would arise out of most proteomics studies where specific subsets of proteins would be identified for particular cell types.

This is not to say that I think publishing genomic sequencing milestones in Nature is inappropriate. Rather, I think you should publish both sequencing and proteomics studies, and apply similar standards for evaluating them. I find it likely that proteomics studies will contain inherently more conceptual insights, since the proteomics will be able to use the genomic sequencing information to make correlations between expression patterns and promoter and other sequence information.

\section{Jeffrey E. Segall}

Department of Anatomy and Structural Biology, Albert Einstein College of Medicine, 1300 Morris Park Avenue, Bronx, New York 10461, USA 